\title{
Bilateral common carotid occlusion with hypoxic ocular sequelae
}

\author{
C. T. HART AND S. HAWORTH \\ Cheltenham
}

A patient is described who was referred with anterior uveitis; following ophthalmic examination the diagnosis of carotid ischaemia was suspected. This diagnosis was confirmed by arch aortography which demonstrated bilateral common carotid occlusion with left vertebral artery stenosis. The aetiology of the occlusive process has been demonstrated at surgery. The patient's preoperative and postoperative progress has been evaluated by means of serial fluorescein angiography.

\section{Case history}

A self-employed milkman, aged 35 years, first presented at the medical outpatient department on August 10, 1969. He stated that 3 weeks previously he had suddenly lost the vision of the right eye. This lasted for approximately one hour and was followed by partial recovery. The eye had become inflamed and photophobic. In addition to his ocular symptoms he had also experienced several episodes of left hemiparaesthesia which lasted for a few minutes at a time. There was no associated weakness. He had also noticed that his jaws felt fatigued and ached when he was eating.

Family history His mother had died of a stroke.

General history He smoked twenty cigarettes a day and occasionally drank alcohol.

GENERAL EXAMINATION

He was a plethoric obese male. The blood pressure was $140 / 90$ in the right arm, and 150/100 in the left; both radial pulses were present, but the carotid pulses were not palpable. Murmurs were noted over the right subclavian artery, over the abdominal aorta, and over both common iliac arteries. There was no other gross abnormality.

OGULAR EXAmination (August 14, i969)

There was no lid swelling or proptosis on either side.

There was marked dilatation of the conjunctival vessels on the right; the cornea was clear and normal. Slit-lamp examination showed a dense flare in the anterior chamber without cells, keratic precipitates, or posterior synechiae. The pupil was dilated to $8 \mathrm{~mm}$. with a markedly diminished response to both direct and consensual light stimulus. There was extensive new vessel formation in the iris which was atrophic and green-brown in colour in contrast to the left iris which was blue. The lens was clear but details of the fundus were blurred by vitreous haze. The disc showed some degree of pallor together with blurring of the margins. The retinal arteries were attenuated and irregular; there was marked venous beading with engorgement. Retinal oedema was most marked in the macular area. There were small scattered haemorrhages, microaneurysms, and areas of new vessel formation, mainly in the midperiphery, and there was a soft exudate temporal to the disc.

The left eye showed some vascular dilatation around the pupillary margin; fundus changes were 
similar to, but less severe than, those of the right eye (Figs I and 2). The eye was otherwise normal. It was considered that these ocular changes were due to ischaemia from carotid obstruction.

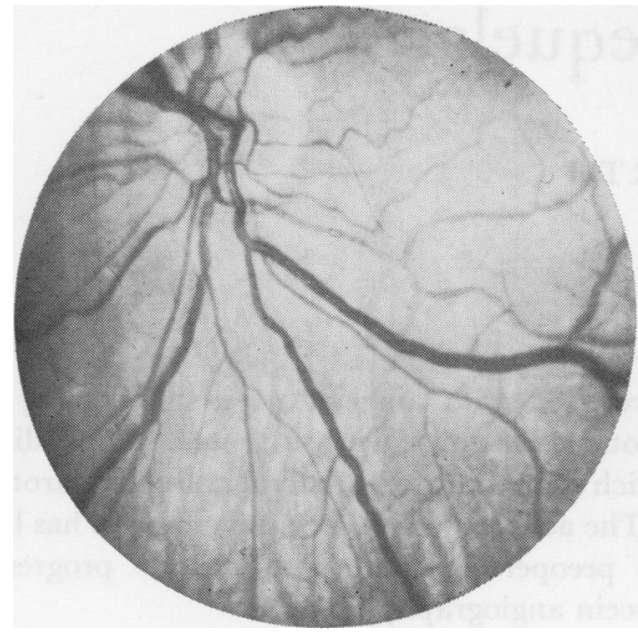

FIG. I Left fundus

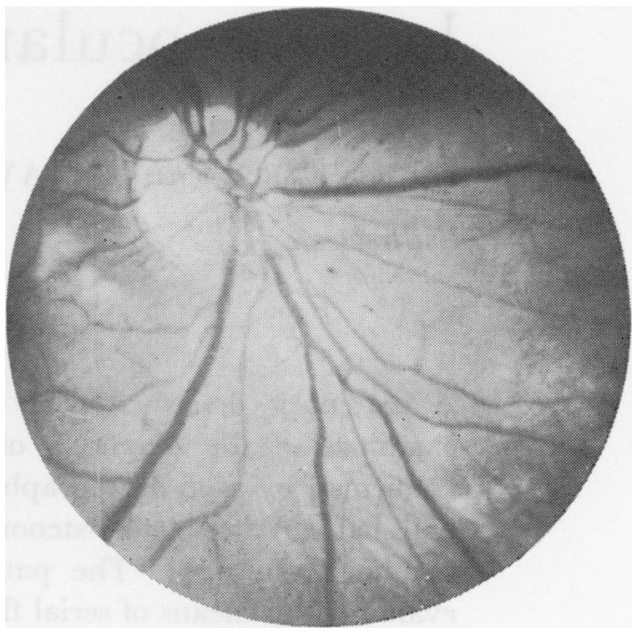

FIG. 2 Right fundus

INVESTIGATIONS

Hb $\quad 16.6 \mathrm{~g}$.; White blood cells $9000 /$ cu.mm.; Erythrocyte sedimentation rate $2 \mathrm{~mm}$./ $\mathrm{st}$ hr Serum cholesterol $346 \mathrm{mg}$./ $100 \mathrm{ml}$.

Blood urea $31 \mathrm{mg}$./100 ml. Serum electrolytes normal.

Total serum protein $6.9 \mathrm{~g} / \mathrm{r}$ (00 ml. with an increase of $\alpha_{2}$ and B globulins.

Wassermann reaction negative.

Nose and throat swab no pathogens isolated.

Arch aortogram (August 22, 1969) performed via the femoral artery. "The common carotid arteries were not demonstrated, both vertebral arteries appeared larger than normal. There seemed to be some stenosis at the origin of the left vertebral artery" (Fig. 3).

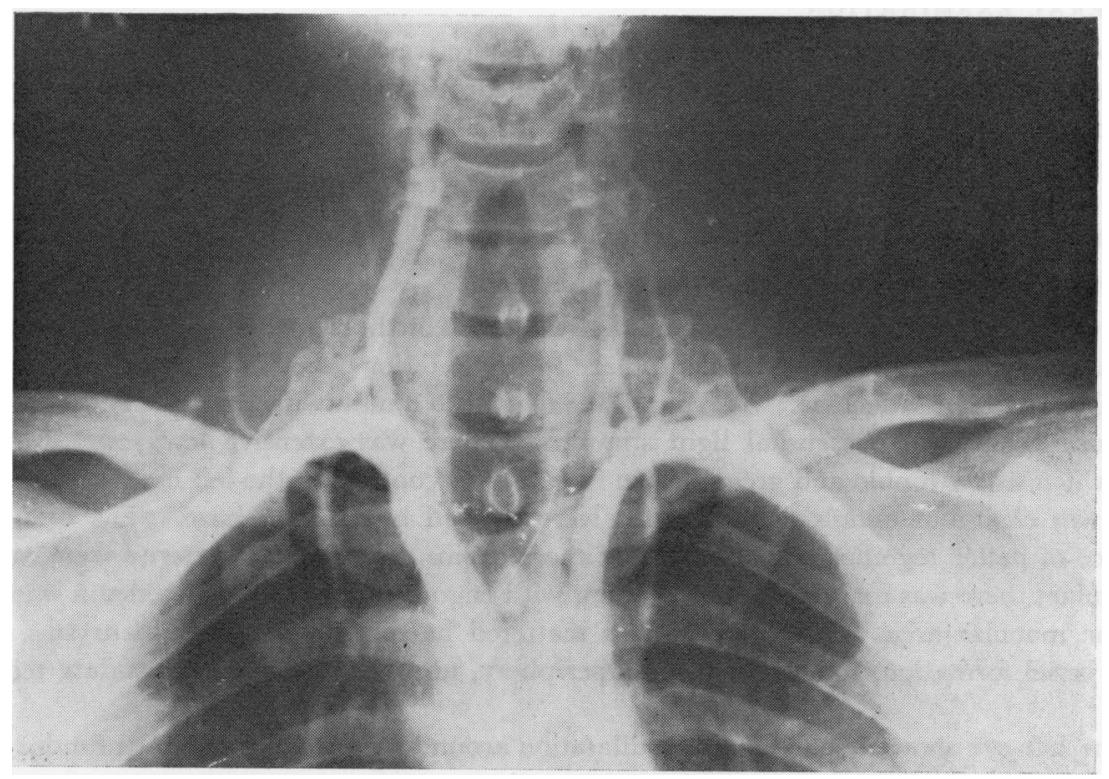

FI G. 3

Preoperative arch aortogram 
OGULAR EXAMination (October 23, 1969)

Increasing prominence of the left iris vasculature was noted, particularly of the circumpupillary arcade. Gonioscopy demonstrated peripheral anterior synechiae formation and new vessels involving the total angle circumference of the right eye; apart from a few visible radial vessels the left angle appeared to be normal. Applanation pressures were $14 \mathrm{~mm}$. $\mathrm{Hg}$ in the right eye and $12 \mathrm{~mm} . \mathrm{Hg}$ in the left. On neither eye was there any movement of the fluorescein meniscus which normally occurs with arterial pulsation. Peripheral fields were full to $1^{\circ}$ and $4^{\circ}$ white targets.

\section{FLUORESGEIN STUDIES}

The fundi were observed and photographed after the injection into an antecubital vein of $3 \mathrm{ml}$. 25 per cent. sodium fluorescein. Events in the two eyes were similar both in appearance and timing. Arterial appearance of dye was noted at 15 sec. (Fig. 4); at $23 \mathrm{sec}$. there was only a minimal appearance of dye in the large veins forming a narrow stream along the vein walls. At $95 \mathrm{sec}$. streaming was still apparent and total venous filling failed to develop (Fig. 5). The picture of the left eye at $5 \mathrm{~min}$. showed extensive leakage of dye from the venous side of the circulation (Fig. 6). The low visual acuity in the right eye can probably be accounted for by the filling defect of the right macular arterioles which supplied the areas of exudate temporal to the disc.

At this stage the patient was referred to St. Mary's Hospital.

(4)

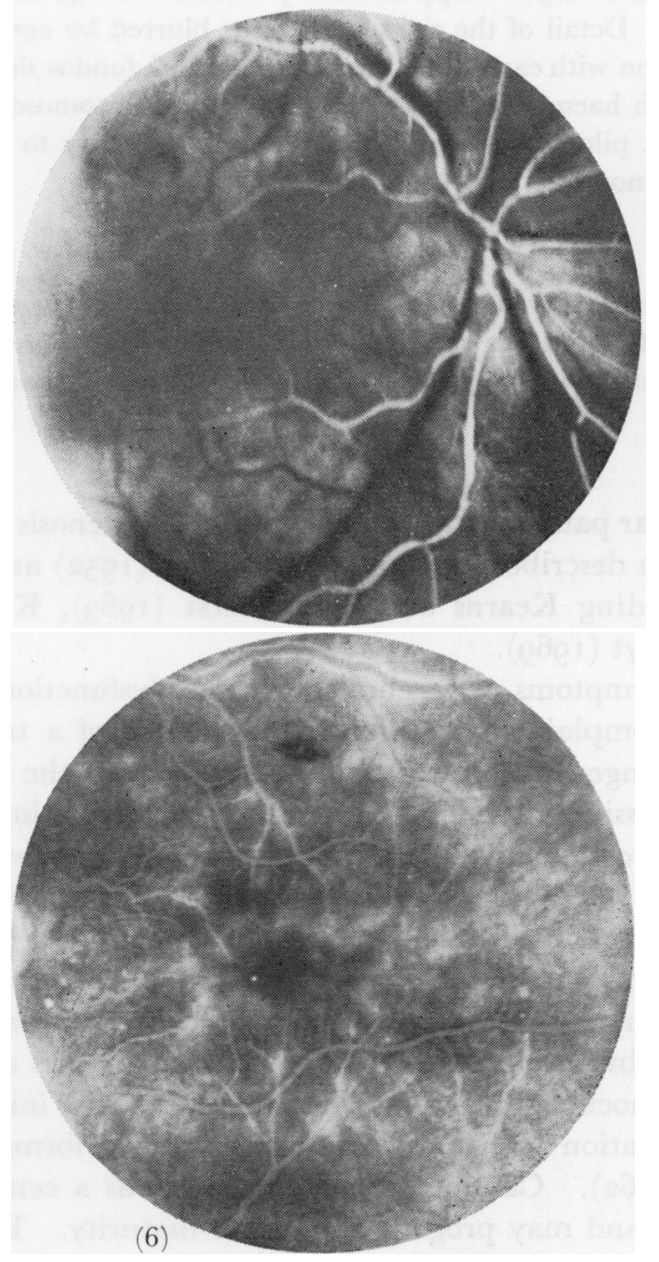

(5)

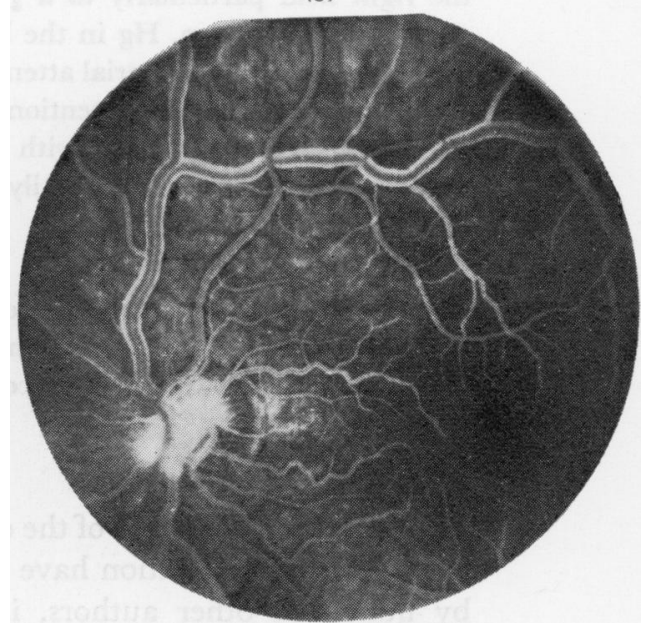

FIG. 4 I5-sec. right fuorescein angiogram; arterial phase, showing marked attenuation

F I G. 5 95-sec. left fluorescein angiogram, showing failure of total venous filling

F I G. 6 5-min. left fluorescein angiogram, showing venous leakage 
OPERATION (February 3, i 970 : Surgeon, Mr. H. H. G. Eastcott)

The left common carotid bifurcation was explored in the neck. The internal carotid and external carotid branches were both patent, but the common carotid artery was thrombosed. The bifur-윽 cation was opened and a Volmar stripper passed down the common carotid artery, and a large cone $\overrightarrow{\vec{F}}$ of atheroma was removed. This produced some flow. The left subclavian artery was then exposed above the clavicle and an 8-mm. by-pass Dacron graft was inserted from the third part of the subclavian artery to the left common carotid bifurcation, the graft being inserted inside in each instance. A good flow was restored in the left internal carotid artery.

\section{PROGRESS}

A postoperative arch aortogram showed that the graft appeared to have occluded postoperatively, although clinically it seemed patent.

\section{OCULAR EXAMINATION (April 27, 1970)}

The visual acuity in the right eye was $6 / 60$ and in the left $6 / 9$ with correction.

There was right bulbar conjunctival engorgement with corneal oedema but no evidence of stromal vascularization. The marked rubeosis of the right iris persisted and no pupillary response was $O$ elicited. Externally the left eye was normal. Perimetry showed some degree of contraction of $O$ the right field particularly to a $1^{\circ}$ white target. Applanation pressures were $42 \mathrm{~mm}$. $\mathrm{Hg}$ in the right eye and $20 \mathrm{~mm}$. Hg in the left. Detail of the right fundus was blurred by corneal oedema, $\subseteq$ but there was marked arterial attenuation with early optic atrophy. The left fundus showed arterial $\underset{\Phi}{\stackrel{D}{\sigma}}$ attenuation and venous distention with haemorrhages and arteriovenous anastomoses in the mid- $\vec{\oplus}$ periphery. He was treated with gutt. pilocarpine 2 per cent. three times a day to the right eye and Diamox Sustets $500 \mathrm{mg}$. daily by mouth.

\section{FLUORESCEIN STUDIES}

These were repeated in the left eye and showed an improved circulation. Early arterial filling occurred at $12 \mathrm{sec}$. and total venous filling at $22 \mathrm{sec}$. Arteriolar calibre was more regular and $\stackrel{\varnothing}{\AA}$ venous distention was reduced as compared with the preoperative pictures (Figs 7, 8, and 9, opposite).

\section{Discussion}

The symptoms and signs of the ocular pathology associated with severe stenosis or occlusion of the carotid circulation have been described by Skipper and Flint (1952) and amplified. by numerous other authors, including Kearns and Hollenhorst (1963), Knox (1965), Э Crock (1967), and Sanders and Hoyt (1969).

The patient may present with symptoms of cerebral or ocular dysfunction separately or in combination. The ocular complaints characteristically consist of a transient loss $\frac{1}{5}$ of vision, often precipitated by changes in posture; pain in and around the eye without $\frac{?}{O}$ photophobia and a gradually progressive fall in visual acuity. On examination there may be lid swelling and dilatation of the conjunctival vessels; the cornea may show endothelial o changes with folds in Descemet's membrane, oedema, and stromal vascularization. $N$ The iris is atrophic and shows increasing prominence of the vasculature; the pupil is $\underset{\omega}{\omega}$ commonly semidilated and sluggish in its responses, with ectropion of the iris pigment? layer around the pupil margin. There is dense flare in the anterior chamber, sometimes with cells and keratic precipitates, but posterior adhesions between the iris and lens are $\stackrel{\Phi}{\Phi}$ not usual (Knox, 1965). The intraocular pressure is often normal or low initially, but a 0 rise in tension may occur in association with new vessel and synechia formation in the

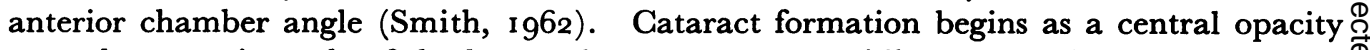
near the posterior pole of the lens and may progress rapidly to maturity. Examination $\stackrel{\varnothing}{\varnothing}$ 


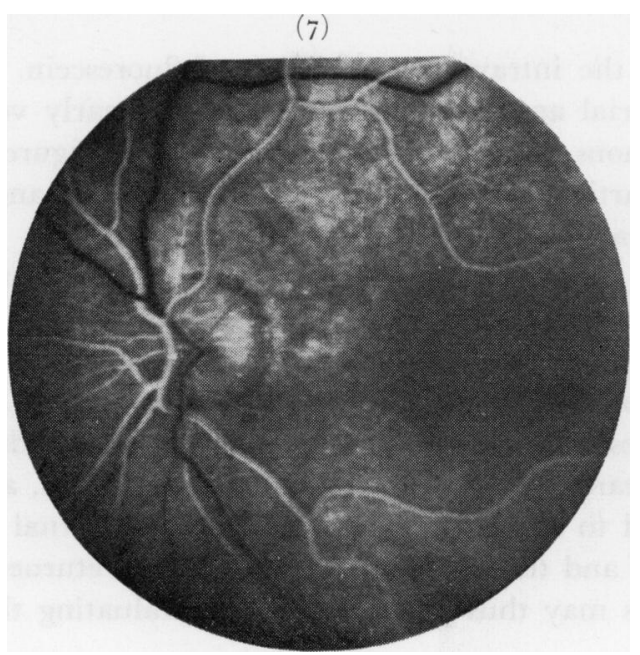

(9)

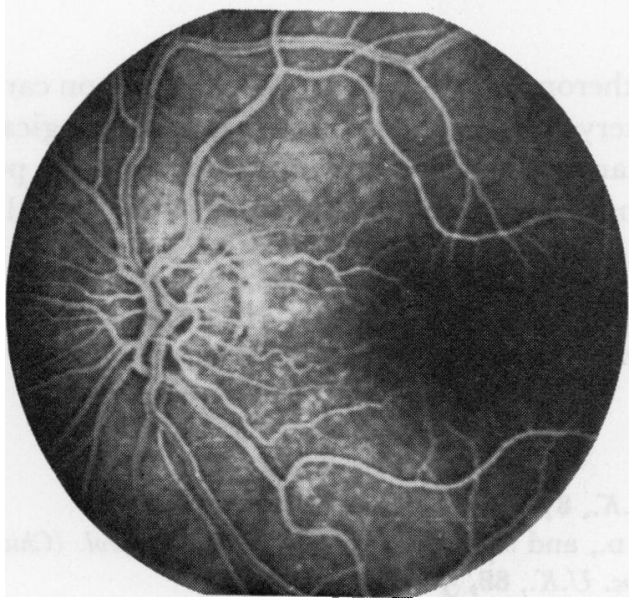

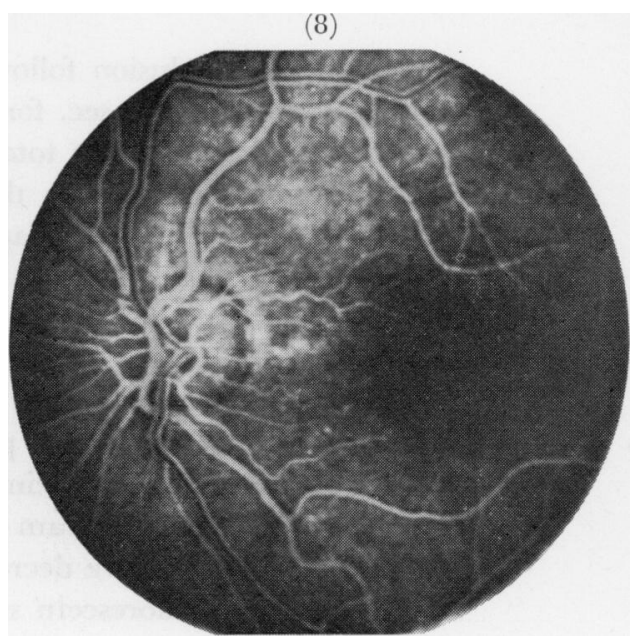

FIG. 7 12-sec. left fluorescein angiogram, showing early arterial phase

FIG. 8 I8-sec. postoperative left fluorescein angiogram, showing venous phase

FIG. 9 22-sec. postoperative left fluorescein angiogram, showing venous phase

of the fundus may show pallor and oedema of the disc; the arteries are narrowed and irregular with venous engorgement and beading. The retina is oedematous, particularly in the macular area, and small scattered haemorrhages and microaneurysms occur mainly in the midperiphery together with small areas of fine new vessel formation (Kearns and Hollenhorst, I963).

Similar changes take place in the anterior segment when surgery embarrasses the ciliary circulation, as may occur with muscle transplantation, detachment surgery, angiodiathermy, and more recently with cyclocryotherapy.

Graham (1968) states that a transient visual loss in one eye with often a contralateral motor or sensory defect is almost pathognomonic of internal carotid artery disease. He stresses the importance of angiographic confirmation. The arch aortogram of the patient we describe shows that his ocular circulation is supplied by his vertebrobasilar system, or via devious anastomotic channels since his entire carotid circulation on both sides is absent. Anciliary information concerning retinal circulation has been derived from serial fluorescein studies. David, Norton, Gass, and Sexton (1966) observed the retinal circulation in normal patients, in those undergoing carotid compression, and in those with 
proven carotid occlusion following the intravenous injection of fluorescein. They give normal figures of $10.9 \mathrm{sec}$. for arterial appearance time, $13 \mathrm{sec}$. for early venous fluorescence, and $17.6 \mathrm{sec}$. for total venous fluorescence. Our equivalent figures, using the same injection technique in this particular patient, are I $5 \mathrm{sec}, 23 \mathrm{sec}$,, and not at all indicating delay in arterial appearance and gross delay in venous filling. David and others (1966) considered that "the best correlate of retinal circulatory insufficiency by this method is slow filling of the veins in the absence of venous obstruction". Hypoxic damage to vessel walls would be expected to be greatest on the venous side of the circulation as it is demonstrated in this patient by the fluorescein leakage (Fig. 7).

The patient's postoperative progress following arterial by-pass surgery has demonstrated an improvement in fluorescein appearance time and retinal vascular status, although the postoperative arch aortogram failed to show patency of the graft. Retinal venous distension and leakage have decreased and the iris vascular pattern has returned to normal in the left eye. Fluorescein studies may thus prove helpful in evaluating the results of arterial surgery.

\section{Summary}

A patient is described with proven atheromatous occlusion of both common carotid arteries and stenosis of the left vertebral artery, who developed transient neurological symptoms and severe bilateral hypoxic ocular pathology. His preoperative and postoperative progress has been evaluated by means of serial fluorescein studies of the retinal circulation.

We would like to thank Mr. A. Stanworth, Dr. A. W. D. Leishmann, and Mr. H. H. G. Eastcott, for their permission to publish this report of their patient. Our thanks are due also to the staff of the Photographic Department at the Royal Hospital, Sheffield, for their assistance with the illustrations.

\section{References}

CROCK, G. (I967) Trans. ophthal. Soc. U.K., 87, $5^{13}$

David, N. J., Norton, E. W. G., Gass, J. D., and Sexton, R. ( 1966) Arch. Neurol. (C.hicago), 14, 28I GRAHAM, M. v. (i 968) Trans. ophthal. Soc. U.K., 88, 5

kearns, t. P., and hollenhorst, R. W. (i963) Proc. Mayo Clin., 38, 304

KNOX, D. L. (1965) Amer. 7. Ophthal., 6o, 995

SANDERs, m. D., and hoyт, w. F. (i969) Brit. 7. Ophthal., 53, 82

SKIPPER, E., and Flint, F. J. (1952) Brit. med. J., 2, 9

smith, J. Lawton (ig62) J. Amer. med. Ass., 182, 683 